\title{
SYSTEM ANALYSIS AS THE GENERAL METHODOLOGICAL BASIS OF TOWN-PLANNING DESIGNING
}

\author{
Andrey Leonidovich Pozdnyakov* Ekaterina Viktorovna Pozdnyakova Marina Mikhaelovana Zvjagintseva \\ Olga Yurevna Barsova
}

Southwest State University, Faculty of Building and Architecture, Kursk, Russia

Proposals for the organization of the territory, the formation of the territorial structure of the "ecological framework" of regional settlement systems are the most important, but not the only result of the application of urban ecology to regional resettlement. It is also necessary to develop a system of common measures to protect air, water and soil and vegetation cover from the impact on the natural environment of urban agglomerations, individual large cities, large recreational and tourist areas. The system of urban ecological restrictions is of particular importance. In this regard, it is extremely necessary to carry out a complex of research and development projects to establish valid urban environmental restrictions, primarily the level of concentration and location of enterprises in various industries, as well as the growth of cities in various natural areas and economic regions of the country. Urboecological restrictions should be based on the threshold values of enterprise capacity, urban population, freight turnover, intensity of recreational flows and loads on the landscape, and regimes of specially protected areas.

Key words: Urboecology, System approach, Urban planning

\section{INTRODUCTION}

Urboecological problems at the macro-territorial level should be resolved in the most general terms and in those aspects that are related to the long-term resettlement, use of the country's territory, its large regions and the possible impact of large urban agglomerations on the environment, as well as the environment (including unfavorable and extreme conditions) on the possibility of resettlement. Constructive proposals here as a whole should be strategic in nature, be directed to the main images for macrozoning of the territory and the development of a fundamental ecological framework for the spatial organization of settlement.

The most important ecological task at this level is the creation of urban development conditions for maintaining ecological balance. Therefore, the zoning of the territory, the rational formation of urbanized and large-scale spaces play a leading role here. Urboecological tasks at this territorial level are solved by the main edge in the framework of the architectural-planning, general geographic and general ecological approach.

\section{PROGRAM-TARGET APPROACH}

Regional resettlement includes research and design of large settlement systems in their mutual influence and, with independent practical output, equips the subsequent levels of design - district planning and urban planning with the necessary arsenal of urban development strategies, in particular in the field of solving the problems of forming the supporting framework of cities, republics and economic regions. The framework, that large cities form, contributes to the effective functioning of the most important territorial links in social production and the creation of urban prerequisites for the activation of social processes [01].

An important element of system analysis is a program-targeted approach that allows to present and formulate the necessary proposals on the basis of a comprehensive analysis of natural conditions, the population, the economy, the choice of an alternative to development, in the form of a purposeful program (or several programs) with well-defined goals, linked to resources, clear time orientation, a reasonably well-founded cybernetic base. The program-targeted approach in the context of a good target orientation in solving a particular problem of economic development and resettlement not only allows to focus the main attention on the main problem and the ways of its solution, measuring the goals and ways of achieving them with resources, but most of all corresponds to the possibilities of economic-mathematical modeling and use in research of specialized programs.

A program-targeted approach to the development of general territorial and regional patterns of resettlement causes the use of special procedures and the use of many methods, the most important of which are:

- qualitative and quantitative definition of the objectives of different levels in the general territorial or regional pattern of settlement, their systematization and assessment of the possible degree of their achievement for the prospective period;

- study of the complex of conditions characteristic for a particular territory, as well as the identification of the main problems of the development of this territory from the standpoint of achieving the set goals; 
- forecast of the most important trends in socio-economic development and changes in the natural environment and their impact on the future development of the economic complex of the territory;

- forecast of natural, material, labor and other resources that determine the degree of achievement of the set goals;

- development and assessment of the main alternatives for the development and location of the economy, protection and improvement of the environment for the future, taking into account their target and resource preferences;

- development of the main areas of settlement;

- choosing the best alternative, identifying indicative resources for its implementation, preliminary linking of available resources with objectives in the framework of priority actions;

- development of integrated programs and subprograms of economic and social development, protection and improvement of the environment;

- development of organizational and technical measures for the implementation of the planned programs.

\section{PROCEDURES AND METHODS}

At each stage of the system approach, when developing specific procedures, special methods should be used to ensure the adoption of the most effective solutions [02]:

- in determining the objectives - expert evaluation, study of exogenous conditions, etc .;

- when identifying problems and trends - factor, correlation and analog analysis, cross-sectional analysis of statistical series, integrated assessment of the territory, etc ;

- when choosing the best alternative to development the "cost-effectiveness-time-feasibility" assessment;

- when developing the development program - various traditional and progressive methods, including the use of the system of economic-mathematical optimization and simulation models.

The objectives of the regional resettlement should correspond to the objective socio-economic patterns of the country's development. We can distinguish three main objectives of the development of the territory under consideration - economic, social and environmental. The main goals are concretized in the system of goals of the first level, the goals of the first level - in the system of goals of the second level, etc. until the goals of the lower levels are differentiated into elementary constructive tasks, the solution of which can provide concrete measures.

Each goal should be formulated initially in the form of a socially necessary function, and then sequentially detailed to specific objects that implement the objective function, which allows you to determine the required amount of resources. When allocating goals for lower levels, they should be ranked according to the criteria for the magnitude of the effect of achieving the goal, as well as their compliance with national goals and the preferred order of their achievement. The ranking of goals should take into account their interrelationship (that is, each goal should contribute to the realization of other goals), as well as competitiveness (the possibility of achieving one goal by reducing the level of achievement of others). The objectives of each level should be commensurate in their scope and significance [03].

It is usually impossible to achieve "cleanliness" in the functional characteristics of the goals. One and the same goal, being either economic, or social or environmental, contains other aspects as well. Nevertheless, it is possible to divide all these goals according to the leading sign. Many of the goals also serve as constraints for other purposes and vice versa (for example, environmental - for economic, etc.).

Analysis of the problems of the development of a particular territory and the impact on its development of the main trends includes a wide range of issues related to the functioning of the economy, the natural features of the territory, the demographic situation, etc. The methodology for the analysis of territorial problems should contain various methods and procedures, the application of various approaches - the establishment of statistical patterns, dependencies and correlations between the sectoral structure of the economy and its location across the territory, determining the conformity of the use of material, labor, natural resources to the existing economic system and its growing needs, conformity of the existing forms of settlement, public services, mass recreation to regional peculiarities etc.

The main criterion for choosing the main directions for the development of a particular territory is the compliance of its economic complex with the conditions determined by scientific and technological progress, on the one hand, and the need for an increasingly serious consideration of the most important features of the territory, including the natural environment, on the other. The purposeful use of the opportunities offered by scientific, technical and social progress makes it possible to outline the cardinal directions for improving settlement in the territory under consideration, to select the most effective strategy and tactics for its implementation, taking into account the progressive trends that have emerged in the development of individual regions and the country as a whole.

It is also important to take into account negative trends, including those that characterize the activation of natural and anthropogenic processes that are unfavorable for the natural environment (changes in the mesoclimate, lowering the groundwater table, decreasing forest cover, erosion processes, etc.).

On the basis of a comprehensive analysis of the current state of the economy and the natural environment of a given territory, trends that can be expected to exert 
influence over the estimated period, the main problems should be formulated that appear in the most general form as the difference between a normative (goal-oriented) and modern condition. The identification of the main problems makes it possible to develop the main promising directions for the development of resettlement [05].

The main directions of settlement, the evolution of the natural environment (including its change as a result of anthropogenic impacts) are projected taking into account not only the diverse trends, but also on the basis of previously defined goals, which at this stage are specified and refined in accordance with specific conditions and the state of exogenous relationships. Achieving the goals essentially means solving the identified problems.

Based on a comprehensive analysis of the natural and anthropogenic components of the territorial system, problems and basic areas of resettlement, the main "mutually exclusive alternatives for the development of resettlement, engineering and social infrastructure, as well as environmental protection strategies, should be formulated and evaluated. Alternatives can be formulated in two ways - as complex or as componentwise. In either case, when formulating alternatives, it is necessary to specify the main directions of settlement taking into account the proportions in the development of various branches of the productive and non-productive sphere.

A complex approach involves the development of alternatives that take into account all aspects of the problem - economic, social and environmental. Such an approach is advisable under conditions of a relatively homogeneous, uncomplicated farm structure, mainly in the conditions of developing new territories. The component approach is characterized by drawing up alternatives separately for the economic, social and environmental components of the territories in accordance with the objectives set. It is more acceptable in conditions of a rather complex economic structure, a large mosaic of the natural environment, mainly in the developed areas.

The choice of the optimal alternative should be made on the basis of an integrated assessment of the target preference, and the level of achievement of a particular goal should serve as a criterion for an evaluation.

The most important operation of system analysis is a qualitative-quantitative comparison of the effectiveness of alternatives. The process of choosing the best of the comparable alternatives is mainly determined by the extent to which the elements of the effect and costs are comprehensively taken into account in each of them. It is important to ensure a clear allocation of all elements associated with the implementation of this alternative (all elements of the process of changing the economy, social sphere and the natural environment in the territory during the period under review). As a complex criterion, the "effect-cost" method is used. This criterion expresses the choice of the alternative to maximize the achievement of goals per unit of resources, taking into account the degree of feasibility (probability) of the accepted alternative at this stage [06].

The development of concrete constructive measures to improve settlement, as well as the final alignment of goals and resources, should be carried out in the program part (program) of the regional resettlement scheme, the most important part of which is the development of a system of constructive measures for its implementation. In the case of an urban-ecological block of a regional scheme, these can be the following types of activities:

- economic (rational structure of industry, agriculture, forestry);

- water management (effective methods of increasing water resources - accumulation and redistribution of precipitation, regulation of runoff and the creation of reservoirs, desalination of sea and mineralized water, etc.);

- forest reclamation (creating protective strips, introduction of resistant to anthropogenic loads of trees, etc.);

- measures for engineering preparation of the territory (combating flooding of the territory, fighting with mudflows, etc.);

- technological (introduction of non-waste and lowwaste technological cycles, etc.);

- activities related to the creation of a system of protected areas (organization of reserves, wildlife sanctuaries, etc.);

- organizational arrangements.

The integrated basis for all these actions is the spatial planning activities (the formation of the ecological framework of the spatial organization of resettlement, ensuring appropriate gaps between developing geographically-aligned cities, etc.).

The success of the program largely depends not only on the correct choice and rational construction of the system of measures, but also on reliable organizational and technical support for the implementation of the program, which first of all includes the material base (availability of advanced technology, production and professional base (availability of qualified personnel carrying out the control and implementation of the program), an effective management system (necessary executive bodies, implementation of automatic control systems, etc.)., a reliable control system and the financing software, etc. 


\section{CONCLUSION}

The solution in the framework of the regional settlement of a number of environmental problems should not be limited to purely town-planning recommendations that help to limit the growth of large cities; it should also include studies in the field of urboecology aimed at an environmentally justified distribution of anthropogenic loads, depending on geochemical and other physico-geographical characteristics of those or other landscapes, as well as recommendations on economic macrozoning of the territory, taking into account environmental factors and the specific features and distribution (depending on the given natural and economic zone) of territories with different degree of urbanization, open spaces, specially protected natural territories and their desired balance, contributing to the preservation of a complete ecological balance in a given region.

\section{ACKNOWLEDGEMENT}

Author thanks the Rector of the Southwest State University, Doctor of Technical Sciences Yemelyanov S.G.

\section{REFERENCES}

1. Vladimirov V.V., Listengur F.M., Naimark N.I. (1974) Some problems and tasks of regional settlement: District planning and regional settlement, pp. 28-35.

2. Kochetkov A.V, Ronkin G.S. (1974) Methodology for the development of complex formation programs and developed group settlement systems: Forecasting the development of a network of populated areas, pp. 30-49.

3. Kochetkov A.V. (1975) The system of urban development management goals and population systems: The use of applied system analysis in the design and management of urban development, pp. 36-54.

4. Avdotin L.N. (1974) A systematic approach to the actual problems of urban planning theory: The use of applied system analysis in the design and management of urban development, pp. 20-33.

5. Pozdnyakov A.L., Zvyagintseva M.M. (2017) General problems of the interdependent development of the biosphere and urbanized environment: Journal of Applied Engineering Science, No. 15/3, pp. 292297.

6. Lavrov V.A. (1966) Cities change their structure: Architecture of the USSR, № 11, pp. 17-21. 